The Universal aid contractors also supplied special types of aids for cases where direct-insertion ear moulds cannot be used or are inadvisable, bone-conduction aids where required (about one case in a hundred), and special high-power aids of wearable type for cases of very severe loss giving high undistorted output for higher than usual speech " inputs." By means of a Universal battery holder, different sizes and weights of $\mathbf{B}$ batteries can be used. Two sizes of A battery or torch cells $\mathbf{C}$ or $\mathbf{D}$ can be used. This provides the necessary compromise between size, weight, and operating costs.

The Government then authorized the establishment of hearingaids clinics at public hospitals to issue, under a qualified staff, free aids to all persons irrespective of age who had an average loss of 35 decibels over the frequencies of 512 to 4,096 inclusive. A the clinics, if the patient wants another aid from any outside firm, it has to be passed by the clinic officers, must carry the New Zealand Standard Mark, and give the written guarantee as to quality, maintenance, and battery costs if the aid is run for six hours a day. This brought to bay and severely limited the activities of vendors whose advertisements and previous disregard of the Standard Specification were tinctured with callous disregard for the welfare of the hard of hearing. The distribution costs were claimed by vendors to be $100 \%$ to $150 \%$ of the wholesale price. This has been eliminated in distribution by hospital clinics. The cost of the latter is offset by the civil rehabilitation of many persons who were socially and economically depressed.

In the annotation is the statement, "It is, however, necessary to stress that many of the deaf included in this number (half a million in Britain) belong to the higher age groups. In them deafness is often due to senile and other degeneration of the internal ear, and so can seldom be satisfactorily corrected by electrical hearing-aids." We also thought so, but have been surprised at the very few who cannot be helped. We have also been surprised at the number of hard of hearing who had not contacted the various branches of the League. At the Auckland clinic, which started on Nov. 1, 1947, of the first 258 applicants for free aids the ages varied from 20 to 90 years. The greatest number were in the age group of 40 to 70 years. Their average hearing loss was 69 decibels.

In general, they had not had a hearing-aid because of their prohibitive costs, or have been dissatisfied with their efficiency, or have been unable to bear the expense of maintenance and battery supply. Most of them have been badly advised or given a hopeless outlook. Above all, they avoided the constant strain of trying to understand or get the context of what the speaker was saying. They have resigned themselves to practical seclusion, and withdrawn from group conversation lest they disclose their infirmity. The fact that they were in the main the first applicants for aids shows the urgency of their plea for help. In the first six hundred issued they form a mass that shows a concealed national tragedy and a hitherto lost legion.

For testing the hearing the clinic has a room that is reasonably sound-proof, and a Western Electric 6A audiometer. The League sound-proof room has an audiometer of local make which is also periodically calibrated and gives similar readings to the Western Electric. The presence of a supervising acoustical engineer has greatly contributed to the smooth running of the department. There are six distribution clinics in the Dominion and others are in the process of being set up. Over $90 \%$ of the patients have taken the Universal aid. Their delight in its efficiency is very gratifying. The other $10 \%$ have amongst them some persons who were unaware of the quality of the Government aid and were induced to give the $£ 15$ subsidy to the vendors and pay up to $£ 30$ additional money.

Determined efforts are being made by practically all hearingaid manufacturers to produce small aids with the batteries contained in the amplifying case. This type of construction increases the battery costs to a level of $£ 20$ to $£ 36$ per annum: The smaller the aid the greater the reduction of safety factors. The New Zealand specification calls for an adaptor to be fitted to these single-pack aids, so that if the increased running costs are disclosed after use the ordinary battery pack can be coupled on to give smaller operating costs and more power if desired by the user.

Our great satisfaction is the practical elimination of the aids of some vendors whose meretricious advertisements delude the unwary, and whose disregard for service and battery supply was a source of disappointment and loss to many.-I am, etc.,

\section{Medical Photography}

SIR,-Dr. R. G. W. Ollerenshaw (May 22, p. 1001) is sceptical of the opinions expressed in my letter (May 1, p. 855). Unlike him I prefer to express my scepticism in English ; it is understood by so many more colleagues. Surely photography is not the only section of art which has not made any material progress during the past 40 years, except in the direction I indicated and as the result of advances in non-visible radiations.

Dr. Ollerenshaw says, "The great bulk of the pictorial work is mediocre," with which I agree, but when he follows with the statement, "Blaming the editorial boards will not help if the material is not good in the first place," I cannot agree. I believe it would help if it ensured efficient representation on those boards, for then that which was not good or accurately described would not be published-a real advance. It is better for the journal and the contributors if quality rather than prejudice decide acceptance.

He suggests that I am being unfair by withholding the name of the hospital whose figures I quoted. Had I felt that they did not contribute point to my argument I should not have used the figures, and I preferred not to give the name lest it be considered that their use was dictated by bias, for I had put up a carefully reasoned but unsuccessful protest against an ultra-modern hospital-the Accident Hospital, Birmingham-being run without a radiologist.

I do not consider that either of the two reasons quoted by Dr. Ollerenshaw are adequate excuse for the exorbitant demands of which he approves. He states, "The photograph is free from any possibility of personal error, which may well change with the observer." I agree that the possibility of error may well change with the observer, but I hardly think that is what he wishes to imply. Does he really believe that the photograph is free from any possibility of personal error? Surely it is the thing which is not free from the possibilities of erroneous interpretation, for the only person who can accurately interpret the photographs of many specimens is he who prepares the specimens. Without his guidance many photographs are liable to multiple and varied interpretations. For instance, of the two photographs reproduced in the Journal of May 22 (p. 993) to illustrate the article on medical photography (good as they are and readily interpreted by the person who prepared them) it can be reasonably claimed that those of us who do not know the specimen consider it a puzzle to find in Fig. 2 a "cavity in which nerve was densely adherent." It certainly is not in the middle of the picture as the object which should at once attract attention.

Fortunately I have been able to secure, by the kindness of Lady Robertson. an album of medical photographs which was made up some 40 years ago for the late Sir John Robertson. and in spite of the age of the prints would submit these with confidence to any unbiased committee for judgment. Had Dr. Ollerenshaw examined publications which contain examples of these illustrations (see British Medical Journal, 1931, 1, 133, and Brit. J. Radiol., 1941, n.s. 14, 79) he would not perhaps have cast the slur contained in his last paragraph. I may say that the author of a book, nearing completion in printing, on pathological conditions of food animals sought permission, even in this modern age, to use some of these and a selection of others to illustrate the book-thus lending support to the old saying. "What Manchester does to-day, Birmingham (with its motto "Forward") did 40 years ago."-I am, etc..

Edgbaston. Birmingham.

JAMES F. BRAILSFORD.

\section{Obstetric Emergency Service}

SIR,-A previous correspondence in the Journal (Dec. 13. 1947 , p. 976 , and Dec. 27,1947 , p. 1055) has revealed a widespread interest in the working of so-called "flying squads" for treating acute obstetrical emergencies in their homes. The experiences of the scheme which has been operating in London for the past ten years under the L.C.C. therefore may be worth recording. It was started in 1939 with the limited object of supplying essential treatment (especially blood transfusion) for acute obstetrical emergencies occurring in the home, which could not safely be moved to hospital. With the exception of two boroughs, which were served by a teaching hospital, the whole of London was covered by 11 L.C.C. hospitals, a clearly 
defined area being allotted to each. Experience showed that roughly speaking two boroughs form a convenient catchment area for a service in which speed in reaching the patient is the main consideration. The usual information was furnished to the general practitioners of London, and in addition all midwives were instructed that, although the service was in no sense an alternative to the use of the medical aid notice, they were at liberty to telephone for the "flying squad" in acute emergencies, such as haemorrhage or collapse, where a practitioner could not be readily obtained and the need was urgent.

The service was little used at first, but calls have increased remarkably in recent years.

\begin{tabular}{|c|c|c|c|c|}
\hline \multicolumn{3}{|c|}{ Year } & No. of Calls & No. of Deaths \\
\hline $\begin{array}{l}1939 \\
1940 \\
1941 \\
1942 \\
1943 \\
1944 \\
1945 \\
1946 \\
1947\end{array}$ & $\begin{array}{l}\cdots \\
\because \\
\cdots \\
\because \\
\because \\
\cdots \\
\cdots\end{array}$ & $\begin{array}{l}\ldots \\
\ldots \\
\ldots \\
\ldots \\
\ldots \\
\cdots \\
\ldots\end{array}$ & $\begin{array}{r}7 \\
1 \\
2 \\
5 \\
23 \\
16 \\
33 \\
67 \\
101\end{array}$ & $\begin{array}{l}\bar{z} \\
\frac{1}{1} \\
\frac{1}{2}\end{array}$ \\
\hline
\end{tabular}

The four deaths deserve comment. In the first case a wrong address was given on the telephone by a frightened messenger, and when the ambulance arrived after some delay the patient was already dead. Another death was due to acute inversion of the uterus. In each of the two remaining cases the team was first asked for, then countermanded, and not asked for again until the patient was moribund.

Analysing the 101 calls in 1947 one finds that 44 originated with doctors, 30 with midwives, 18 with nursing homes, miscellaneous 3, caller unknown 6 . The great majority of the patients were suffering from post-partum haemorrhage with or without retention of the placenta. (Cases of ante-partum haemorrhage are taken directly into hospital, as it has hardly ever been thought desirable to start treatment in the home.) 73 of the 101 patients required immediate blood transfusion, and 58 were brought into hospital as needing further treatment or nursing care unobtainable in their homes. The geographical distribution of the calls is curiously irregular. St. James Hospital, Balham, has had 33 in 1947-more than three times as many as the next hospital on the list.

To provide a team available at a few minutes' notice at any hour is undoubtedly a serious burden on a maternity unit, particularly if they are as understaffed as the L.C.C. wards have been of recent years. The supply of blood has presented difficulties, but these have now been overcome. It is essential that every member of the staff, from the consultant to the gate-porter, should be made aware of "the drill " and of its importance in life-saving from the moment they take up duty. a point sometimes overlooked with frequently changing staffs. Our calm and courteous ambulance switchboard operators have played no small part in the smooth running of the scheme. Callers are often almost incoherent from anxiety. In at least two instances they got on to Scotland Yard and were disentangled with difficulty.

In a very few instances there has been an undoubted abuse of the service (as for example when the team has been summoned to give an anaesthetic or to do a trivial perineal repair). no doubt owing to a misunderstanding of its functions. Where a genuine error of judgment has led to an unnecessary call it is important to refrain from complaint. The L.C.C. has wanted practitioners or midwives to feel free to use the service where they are in any real doubt or anxiety. The fear that obstetrical procedures-which should properly be conducted in hospitalmight be undertaken in the home has proved entirely without foundation. On the other hand, the service has undoubtedly saved the lives of many women for whom an immediate journey to hospital might have proved fatal.-I am, etc.,

The County Hall, London, S.E.1.

LETITIA FAIRFIELD.

\section{New Conception of Angina Pectoris}

SIR,-The present theories of the production of pain in cases of angina pectoris certainly do not cover all the known facts. For this reason the paper by Dr. R. Wyburn-Mason (May 22, p. 972) was of interest in trying to correlate the various aspects of this controversial subject. I would, however, like to raise one point which he did not discuss. In support of his theory he states that nicotine causes generalized vasodilatation and is a well-known cause of anginal attacks. Surely, then, amyl nitrite might also be expected to produce similar attacks, and yet it is dramatic in its relief of these symptoms. I would be interested to know how Dr. Wyburn-Mason correlates this fact with the rest of his observations. - I am, etc.,

Edinburgh.

NeIL Gordon.

\section{Acute Intussusception in Childhood}

SIR,- - I have been interested in the correspondence on this subject. I have seen 25 cases with deaths. I notice that no one has called attention to the peculiar facial aspect of infants suffering from this trouble. It is very like the facial aspect of children with hydrocephalus. This sign seems to me to be almost pathognomonic of intussusception. In one case it was the only sign beyond vomiting which I saw for 24 hours ; there was no pain, not even the initial cry. At the end of 24 hours I got a smear of blood on my finger-tip.

I took the mother and infant into hospital, but the surgeon, who had operated on 11 . cases of intussusception, refused to operate. He did so when the mother asked him. Half an inch of ileum was intussuscepted into the colon and was already adherent. The infant made a good recovery.-I am, etc.,

Birmingham. ROBERT ANDERSON.

\section{Juvenile General Paralysis}

SIR,-In reply to Dr. Robert Thompson (May 22, p. 999), who has suggested that in the case of juvenile general paralysis which I described (May 8, p. 881) the remission was from the symptomatic fits of congenital syphilis, I would like to point out that, whereas I agree that mysterious remissions do occur, in this case it was not only the fits which cleared up. In the original illness there were other factors which strongly suggested the presence of juvenile general paralysis-for instance, the profound personality change was quite characteristic-and one must also take into consideration the motor incoordination and marked slurring of speech which was present. As far as one can ascertain this original illness completely resembled the later relapse.

As opposed to this, the patient which Dr. Thompson described was " a well-developed, intelligent boy with no stigmata of any kind." I would submit, therefore, that there was more than a reasonable probability that my patient was indeed suffering from juvenile general paralysis from an early age.-1 am, etc.,

$$
\text { Porsmouth. }
$$

$$
\text { W. LidDell Milligan. }
$$

\section{Conscription of Women Doctors}

SIR,-It is common knowledge that there has been great difficulty ever since the end of the war in meeting the requirements of the armed Forces for consultants and specialists, but the Medical Women's Federation understands that the Services Commmittee of the Central Medical War Committee is now finding the same difficulty with regard to general duty officers.

It will be remembered that, whereas during the war women doctors were conscripted with their male colleagues, this policy was reversed in 1945, and that since then no women at all have been called up. The Medical Women's Federation, with the support of the British Medical Association, has always upheld the principle that in medicine there should be no differentiation solely on account of sex, and has contended that this applies equally to duties and to privileges and that women doctors ought not to escape a liability which presses hardly on their male colleagues. Repeated representations have been made to the Government, and last year an unsuccessful attempt was maçe to get the National Service Bill amended during its passage through Parliament. The arguments raised against the conscription of women doctors have always appeared unconvincing to the Federation, but a difficulty in pressing the case has hitherto been that there were more than enough male general duty officers available to meet the needs of the Services.

This situation is now entirely changed, and it is understood that the Services Committee of the Central Medical War Committee has had to consider new means of increasing the inflow 